\title{
LA PROVINCIA DE ANTOFAGASTA. CREACIÓN Y CONSOLIDACIÓN DE UN TERRITORIO NUEVO EN EL ESTADO CHILENO: 1888-1933
}

POR

\author{
JOSÉ ANTONIO GONZÁLEZ PIZARRO \\ Universidad Católica del Norte \\ Antofagasta, Chile ${ }^{1}$
}

Se examinan los diversos factores - geográficos, económicos, demográficos, politicos y legales-que incidieron en el debate parlamentario y posterior creación de la provincia de Antofagasta durante el gobierno de Balmaceda. Entre los aspectos diferenciadores que exhibió la provincia respecto a otros territorios chilenos, resaltó la herencia del periodo del la administración boliviana, en lo concerniente a las facultades municipales que incidió en el fortalecimiento de un discurso regionalista ante las pretensiones del estado chileno, respecto a la uniformidad jurídica. Se pasa revista a las diversas propuestas de estructuración político-administrativa del territorio de Antofagasta y las distintas modificaciones que afectaron a éste desde 1888 hasta 1933, poniendo énfasis en la complejidad del territorio en el ámbito internacional, nacional y local.

Palabras clave: Chile, provincia, desierto de Atacama, Antofagasta, leyes chilenas.

\section{INTRODUCCIÓN}

La ocupación de Antofagasta por las fuerzas armadas chilenas, el 14 de febrero de 1879, significó la primera acción que daría lugar al inicio de hostilidades entre Chile y Bolivia - y posteriormente contra Perú-, pero, a la vez, el inicio de una problemática para el gobierno de Santiago de cómo debería integrarse el territorio del desierto de Atacama al ordenamiento político-admi-

1 Doctor en Historia por la Universidad de Navarra. E-mail: jagonzal ${ }^{\circ} u c n . c l$. El trabajo forma parte del proyecto Fondecyt n. ${ }^{\circ} 1051093$, año 2008 y de la Iniciativa Científica Núcleo Milenio «Ciencia Regional y Políticas Públicas». 
nistrativo de Chile. Toda el área que comprendía el desierto de Atacama supuso, después de concluida la guerra en 1884, varios desafíos tanto para los habitantes de Antofagasta, en su gran mayoría chilenos, como para las autoridades políticas nacionales. Inicialmente se debió afrontar lo que significaba para los residentes de la urbe principal y del hinterland minero la incorporación del desierto de Atacama a la soberanía chilena; territorio que se distinguía en el funcionamiento peculiar del municipio (heredado del tiempo de la administración boliviana), tan distinto a como operaba en Chile en el ejercicio de algunas facultades administrativas. Ligado a este planteamiento estuvo la conceptualización de la reivindicación del territorio, como respuesta formal a la violación por Bolivia del Tratado del 6 de agosto de 1874, en su artículo 4. ${ }^{\circ}$ El Tratado en cuestión fijaba el paralelo $24^{\circ}$ de latitud como frontera. Éste fue un nivel que debió encarar el gobierno de Chile, principalmente ante las vivas protestas de la población antofagastina ${ }^{2}$.

Conexo con lo aseverado surgió el debate en torno a si Chile podía incorporar el mencionado territorio de Antofagasta y su hinterland como provincia, cuando sólo existía el Tratado de Tregua entre Chile y Bolivia de 4 de abril de 1884. Una tercera arista sobre la creación de la provincia de Antofagasta apuntó a que sin articulación administrativa del territorio en igualdad de condiciones a las provincias chilenas no podía haber representación política de la zona en el Congreso Nacional. ¿Cómo armar un territorio provincial donde a la vez se cruzaban dos sistemas jurídicos distintos?

El dilema y la consecuente discusión política en Antofagasta como en Santiago discurrieron en buscar soluciones alternativas para poder «adicionar» también una población suficiente que cumpliera con las exigencias constitucionales para elegir un senador. Centraremos nuestro trabajo en cuatro materias:

1. El territorio mirado desde la dualidad reivindicación v/s anexión. La perspectiva regionalista. 2. El territorio mirado desde la dualidad jurisdicción nacional $\mathrm{v} / \mathrm{s}$ tratado internacional. La perspectiva internacional. 3. El territorio mirado desde la dualidad uniformidad $\mathrm{v} / \mathrm{s}$ diferencia territoriales. La perspectiva nacional. 4. El territorio mirado desde la configuración provincial y divisiones departamentales. La perspectiva desde la nueva institucionalidad de 1925.

2 Sobre este tópico, González Pizarro, 2005: 70-80. 


\section{EL TERRITORIO PERCIBIDO DESDE LA PERSPECTIVA REGIONALISTA}

La población chilena, sobre el $85 \%$ del total en Antofagasta hacia 1879, había sido clave en la configuración cultural del territorio ${ }^{3}$. Primeramente, desde la fundación de la Municipalidad en 1872, decidiendo el rumbo de constante desarrollo de la urbe con la necesaria regulación de sus disímiles actividades y también con las presiones conjuntas de comerciantes y mineros de la zona respecto a la opción por el puerto de Antofagasta en vez de Mejillones como salida de exportación de la minería de plata de Caracoles desde 1870.

Cuando se verificó la ocupación militar chilena, la proclama de tal acción reveló meridianamente el sentido de ésta: era volver a situar el paralelo $23^{\circ}$ en la soberanía chilena. El tenor fundamental de la nota reunía la conexión de la ocupación con la reivindicación:

Antofagasta, 14 de febrero de 1879.- - Señor Prefecto.

Considerando el Gobierno de Chile, roto por parte de Bolivia el Tratado de 1874, me ordena tomar posesión con las fuerzas de mi mando, del territorio comprendido en el grado $23^{4}$.

Esta idea estaba ampliamente socializada en la población chilena de Antofagasta. De ahí, que no fue sorprendente que el ministro de Relaciones Exteriores, Alejandro Fierro, la empleara como núcleo central en su exposición de 18 de febrero de $1879^{5}$. Los miembros del municipio antofagastino utilizaron la noción de la «reivindicación» en sus sesiones, desde el mismo año de 1879. Matías Rojas Delgado, adalid del regionalismo nortino, expuso su pensamiento en un libro intitulado El desierto de Atacama i el territorio reivindicado, que vio luz en Antofagasta en 1883. Para los habitantes de Antofagasta ésta constituía lo más progresista que mostraba el carácter chileno: en sus capitales, en sus obreros y la industria establecida; esfuerzo que se remontaba a la promulgación de la ley de guano de 1842 que llevó a ocupar Mejillones por

3 Hacia 1875 en base del censo practicado por la Municipalidad de Antofagasta, la ciudad contaba con una población de 5.384 habitantes, de los cuales 4.530 eran chilenos, o sea un 84,13\% del total. Cf. Rojas Delgado, 1883: 363.

La población chilena se acrecentó rápidamente. En 1881, se practicó un censo donde se reconoció un explosivo crecimiento demográfico, en torno a los 10.000 habitantes. Cámara de Diputados, Legislatura Extraordinaria (L.E.): 9 de enero de 1882.

4 Isaac Arce, 2004: 369.

5 Ministro de Relaciones Exteriores de Chile, 1879: 17.

En cuanto al concepto de «reivindicación» en la época remito a González Pizarro, 2005, vol. 1: 335-392. Horacio Andaluz, 2002: 92-99, discute la legitimidad de la «reivindicación» chilena. 
la armada chilena ${ }^{6}$. Pero, la reivindicación tenía sus matices. Lo obrado bajo la liberalidad del gobierno de Bolivia, en cuanto a otorgar «facilidades» administrativas a la municipalidad de Antofagasta, se consideró que debía perdurar bajo la administración chilena. Esto afectaba a la propia sociedad y la actividad minera variada en la zona.

Esta defensa quedó muy patente cuando se observó la manera cómo consideró el gobierno de Santiago al territorio de Tarapacá. Tarapacá constituía una clara anexión al territorio nacional. Los títulos esgrimidos eran distintos. Jamás había sido de Chile, como sí, parte del territorio septentrional nacional, el desierto de Atacama. Sin embargo, la provincia de Tarapacá había sido establecida por ley n. ${ }^{\circ} 2.2 .61$ de 31 de octubre de 1884 inmediatamente después de concluido el Tratado de 20 de octubre de 1883, entre Chile y Perú, firmado en Ancón, y que fue ratificado por la Asamblea Nacional de Perú el 8 de marzo de 1884, donde se cedía «perpetua e incondicionalmente» la mencionada provincia $^{7}$. En consecuencia, Tarapacá pudo contar con un senador, Luis Aldunate, para el periodo de 1885-1891. La organización de Tarapacá conllevó una atención legislativa favorable para su industria del salitre, en desmedro de las salitreras localizadas al sur del río Loa.

La exposición de esta dualidad de concepciones, en base de las ideas de la reivindicación y de la anexión, fuente de la búsqueda de la erección de la provincia de Antofagasta, la llevó a cabo Rojas Delgado:

Si pasamos del territorio chileno propiamente dicho al reivindicado por nuestras armas, nos encontramos con que si se encuentra en condiciones mui superiores a este, lo está en un estado mui inferior a las del Territorio de Tarapacá, que era peruano; donde estando implantada esta industria desde largos años atrás, se cuenta con vías más fáciles i menos costosas i con caliches mui superiores en lei i con calidades especiales, que hacen su elaboración mucho menos costosa que en Antofagasta, i por consiguiente enormemente menos que en el territorio al sur del paralelo $24^{\circ 8}$.

Precisamente, amparado en esta noción clave, los antofagastinos hicieron valer las justas demandas por contar con representación política del territorio ${ }^{9}$ como la revisión de la ley de 1 de octubre de 1880, nefasta para los intereses salitreros del sur del paralelo $24^{\circ}$, pero muy favorable para la potente industria

${ }^{6}$ Cf. El Catorce de Febrero, Antofagasta, 12 de noviembre de 1879.

7 Mario Barros Van Buren, 1990: 466-468.

8 El Industrial, Antofagasta, 16 de agosto de 1881. Los destacados son míos.

9 El diputado Pedro Montt defendió tal derecho en la Cámara de Diputados, «como cualquier otro departamento de enviar sus representantes al congreso». Cámara de Diputados, Legislatura Extraordinaria (L.E.): 29 de octubre de 1881. 
calichera de Tarapacá ${ }^{10}$. Esta concepción del título de la reivindicación para los habitantes chilenos del despoblado de Atacama, se proyectó en el pensamiento nortino hasta mediados de 1940.

\section{EL TERRITORIO EXAMINADO DESDE LA PERSPECTIVA INTERNACIONAL}

El establecimiento de la provincia de Tarapacá estuvo en gran medida despejado, en sus connotaciones diplomáticas, por dos aspectos esenciales: a) el Tratado entre Chile y Perú, rubricado en Ancón, había declarado en su artículo 1, el restablecimiento de las «relaciones de paz y amistad entre las repúblicas de Chile y del Perú» y b), la cesión «perpetua e incondicionalmente» de la provincia de Tarapacá.

La situación del territorio del desierto de Atacama, observado desde el prisma del derecho internacional, era distinta. Cuando el diputado Domingo Arteaga Alemparte propuso, en la sesión extraordinaria de 3 de enero de 1880, un proyecto que solicitaba al gobierno «que declare incorporado a la República los territorios conquistados por las armas chilenas en la actual guerra», se encontró con tres respuestas que cerraron la discusión de la propuesta. Una, la de Enrique Mac Iver, que planteó que el único título que se podía alegar era que los territorios «se encuentran en nuestro poder», lo que nunca aceptaría «como un título de conquista, el derecho de la fuerza. No aceptaré jamás que la incorporación de Tarapacá sea a título de conquista». Su planteamiento era que eventualmente se podía exhibir otros títulos que se acercaban a los esgrimidos para la reivindicación de Antofagasta ${ }^{11}$. Dos, la de Luis Aldunate, que vinculó los principios del derecho internacional con las obligaciones que debían observar los ejércitos ocupantes del territorio enemigo, lo que significaba que el ejército ocupante «no puede considerarse sino como usufructuario del país que domina. La nuda propiedad de esos territorios permanece vacante hasta que la conquista llegue a ser definitiva» ${ }^{12}$. La tercera, fue dada por Do-

10 El diputado por Vallenar, Nicolás Naranjo, planteó en 1881 la revisión de la ley de eximir del impuesto de exportación a las salitreras al sur del paralelo $24^{\circ}$ Cámara de Diputados, L.O. y E. 29 de agosto de 1881.

11 «Tenemos otros muchos (títulos) más sagrados para llegar al mismo fin». El que nosotros tengamos derecho a ocupar a Tarapacá porque «nuestros nacionales han creado aquellas riquezas, porque ellos han formado para la civilización aquel territorio en virtud de su esfuerzo, de su sangre, de sus huesos, es una verdad como cualquiera otra, será tal vez una consideración que podamos alegar en tiempo más oportuno». Cámara de Diputados, L.E. 3 de enero de 1880. Destacados míos.

12 El raciocinio de Aldunate, apoyado en autores, como Lieber, autor de las «Instrucciones 
mingo Santa María, ministro del Interior, quien reconocía que el susodicho proyecto de acuerdo obedecía a un acendrado patriotismo, «creemos que es inoportuno i que su discusión es inconveniente». Empero, en la sesión extraordinaria de 8 de enero de 1880, se impuso la sugerencia del gobierno de Aníbal Pinto, que obtuvo un apoyo de 37 votos de no discutir el proyecto ante 4 votos a favor, donde figuró Carlos Walker Martínez. En efecto, el 4 de abril de 1884 se firmaba un Tratado entre Chile y Bolivia. Era el marco del fin de las hostilidades entre ambas repúblicas: un Pacto de Tregua. El territorio «comprendido desde el paralelo $23^{\circ}$ hasta la desembocadura del río Loa» seguiría bajo la «sujeción (del) régimen político y administrativo que establece la ley chilena» ${ }^{13}$.

El Tratado, con el Protocolo adicional de 30 de mayo de $1885^{14}$ obligó a Chile en la zona del despoblado a determinadas obras ${ }^{15}$. Simultáneamente el Congreso Nacional debatió otras leyes a favor de los poblados del desierto de Atacama como también de la articulación vial entre los centros mineros y los puertos. En este contexto, cuando se discuta el proyecto de ley de creación de la provincia de Antofagasta, las únicas representaciones provenientes del desierto de Atacama fueron los diputados Nicolás Peña, por Antofagasta, y Vicente Grez, por Taltal.

Para el poder Ejecutivo, el proyecto de ley que establecía la provincia de Antofagasta, era un «asunto sencillo...no da tema para discusión de mas de un cuarto de hora», había asegurado el ministro del Interior, D. Pedro Lucio Cuadra, a la Cámara de Diputados, el 5 de junio de 1888. El Senado lo había despachado y la Comisión de Gobierno informado favorablemente. El proyecto de ley, que comprendía 18 artículos ${ }^{16}$, señalaba en su artículo inicial:

Créase la provincia de Antofagasta, cuyos límites serán: Al norte i este, la línea que según la lei de 31 de octubre de 1884 determina el límite sur de la provincia de Tarapacá, desde la boca del río Loa hasta el volcán Túa; desde este punto la que fija

para los ejércitos de los Estados Unidos», Blunschly, lo llevaba a exponer que, «La jurisdicción nacional del país ocupante puede modificar i aun abolir las leyes del país ocupado; pero sólo el tratado de paz o la cesación definitiva de las hostilidades tienen el mérito de dar carácter de permanencia a los actos del ocupante i títulos de legitimidad a su dominio». Cámara de Diputados, L.E. 8 de enero de 1880. Luis Aldunate fue posteriormente ministro de Relaciones Exteriores del gobierno de Domingo Santa María.

13 Barros Van Buren, 1990: 470.

14 Cf. Protocolo complementario del Tratado de Tregua entre Chile i Bolivia, de 30 de mayo de 1885, en http://www.bcn.cl/lc/tinterna/index_html.

15 Véase el Informe de la Comisión de Gobierno, de 31 de diciembre de 1887, Cámara de Diputados, L.E. 3 de enero de 1888.

16 Informe de la Comisión de Gobierno, 30 de enero de 1887, Cámara de Diputados, L.O. 5 de junio de 1888 . 
la cláusula 2. ${ }^{\circ}$ del Tratado de Tregua celebrado con la República de Bolivia, hasta la intersección de la recta que une las cumbres de Licancaur i Sapaleri con la línea que antes de dicho tratado separaba a Bolivia de la Argentina; i en seguida esta última línea hasta la cumbre mas alta del cerro de San Francisco. Al sur i oeste, los límites oriente i norte que la lei de 14 de enero de 1884 asigna al departamento de Chañaral, i el océano Pacífico.

La decisión de organizar el territorio como provincia generó diversas consideraciones. El meollo fue si, mediando solamente un Tratado de Tregua, el gobierno chileno podía incorporar Antofagasta y su hinterland a su sistema político-administrativo. La voz más firme en cuestionar la oportunidad de la aprobación de la ley que formaba la nueva provincia provino del líder conservador Carlos Walker Martínez. Su intervención fue la única que vinculó el tema en el marco de las relaciones entre Chile y Bolivia. Sin duda, había modificado su parecer de 1880. Ahora, para él, además de acoger la iniciativa dentro del régimen administrativo de la República, había que hacer «algunas observaciones bajo el punto de vista político, dentro de la honrada aplicación de los principios del derecho internacional... que nos corten dificultades en lo futuro con Bolivia».

Para el diputado por Maipo debía examinarse en el marco del Tratado de Tregua dos nociones claves: el dominio diferenciado de la posesión del territorio. En su opinión: «El Tratado de Tregua del 84 no nos dio el dominio de aquel territorio; nos dio únicamente la posesión, la mera tenencia; i no podía ser de otra suerte desde que ese pacto fue simplemente de tregua i no de paz definitiva... La posesión nos da ciertos derechos limitados por la voluntad del dueño, de manera que estamos impedidos de hacer todo aquello que signifique dominio, bajo el doble aspecto de político i “ánimo de señor”, como dicen los tratadistas. Enajenar terrenos fiscales, por ejemplo, crear representación electoral, etc., etc., entran en esa calificación. En aquélla, manejar los intereses locales, crear juzgados, administrar, en una palabra. Situación, pues, que se produce en condiciones enteramente distintas en uno i otro caso. La doctrina que apenas insinuó es evidente, la única sostenida como correcta en todos los libros escritos sobre la materia. El pacto de tregua la consagró para nosotros clara i palmariamente».

Walker Martínez asentía el derecho de Chile de organizar su régimen de gobierno y llevar a cabo el desarrollo de los variados poblados; sin embargo, cuando esa orientación procuraba ordenar la provincia a rango constitucional avanzaba hacia «territorios de que es mero ocupante» donde el Estado no se colocaba «en igual situación de buen derecho» porque esa directriz y procedimiento eran propios del dominio eminente. Chile no debía atropellar, olvidar o desconocer los principios del derecho internacional. Y acotaba: 
Anexar a nuestro territorio el de Antofagasta, en los términos en que está redactado el proyecto, es resolver por nosotros mismos el problema; i hai un axioma de derecho que establece que las cosas se deshacen de la misma manera que se hacen, así como en los negocios privados i ordinarios de la vida, que habiendo contratado dos no puede uno solo de los contratantes deshacer por sí solo el contrato celebrado sin la voluntad del otro. ¿Qué significa decir simple i sencillamente «se crea la provincia tal o cual»? Nada más ni menos que decir: «la provincia tal o cual es nuestra, pertenece a nuestro territorio, tiene derechos políticos como las demás, forma parte integrante del resto de la República». Eso es dominio.

Para el mencionado parlamentario, el gobierno y el poder legislativo debían propender a tener buenas relaciones con todo el mundo, «sobre todo con Bolivia, nuestra vencida de ayer, nuestra amiga de hoy, nuestra hermana siempre» $\mathrm{y}$, en tal predicamento, había que conciliar las medidas de buen servicio administrativo de Chile — «i por eso acepto i creo conveniente la creación de la nueva provincia» - con el respeto del derecho ajeno, al prestigio que gozaba Chile en el exterior y asumir el carácter transitorio de lo debatido.

El ministro de Relaciones Exteriores, D. Demetrio Lastarria, sostuvo que la nueva provincia iba a comprender «territorios de nuestro dominio, como son los departamentos de Antofagasta i Taltal, i de territorios respecto de los cuales no tenemos sino el mero imperio».Y en ello no existía impedimento alguno, pues el departamento de Tocopilla iba a estar contemplado en un artículo posterior a la ley en referencia. Pero había una razón más gravitante: no se podía «quedar más atrás de a donde fue el pacto de tregua», donde Bolivia había reconocido implícitamente el dominio de Chile al sur del paralelo $23^{\circ}$ y «la agregación de Antofagasta a nuestra nacionalidad fue hecha por lei del año 79. De ahí que no podemos volver atrás». Se aludía a la ley de 2 de mayo de 1879 que creó el departamento de Antofagasta.

Walker Martínez replicó que el tema no era el departamento de Taltal ni tampoco «el pedazo de tierra de Antofagasta mismo», sino «al territorio no reivindicado, no anexado, sino simplemente dejado en poder de Chile por la tregua de 1884». Su argumentación ponía al descubierto con nuevos ejemplos la fuerza de la distinción entre dominio y posesión:

Una lei, por ejemplo, de Bolivia, impone el acuerdo del Congreso para vender propiedades municipales; otra lei impide la fundación de censos; ¿se consideraría Chile con derecho a imponer censos i vender tierras municipales en aquel territorio, que todavía es boliviano? La cuestión es grave, i merece estudiarse. Por eso, para evitar aun esos peligros, yo he creído que orillar esta cuestión es salvarla. No seamos lijeros, no andemos con precipitación, que un mal paso en la política internacional suele abrir un abismo... Se nos habla de que el pacto de tregua permite lo que se va a hacer. Creo que en ello hai un error. El pacto de tregua se refirió a las leyes administrativas, no a las que traen consigo carácter de dueño. Es justamente la lectura de aquel pacto la que me ha movido a adelantar estas observaciones, porque me 
parece que la justicia debe ser igual, lo mismo para el chico que para el grande, para Bolivia como para cualquiera otra gran potencia europea ${ }^{17}$.

La moción de Carlos Walker Martínez, un hombre oriundo de Copiapó, conocedor del desierto de Atacama, fue rechazada por 59 votos contra 8, en la sesión de 9 de junio de 1888.

Bolivia protestó ante la Cancillería chilena de la iniciativa de crear la provincia de Antofagasta ${ }^{18}$. La situación del desprendimiento del territorio de la soberanía boliviana afectó la condición eclesiástica de la zona, que fue hasta 1928 un Vicariato Apostólico ${ }^{19}$. Pero quedaba todavía otro tema que afectaría los límites andinos de la nueva provincia. Nos referimos a la pérdida de la Puna de Atacama.

Desde la creación de la provincia de Antofagasta varias localidades situadas en lo que el ingeniero chileno Alejandro Bertrand ${ }^{20}$ denominó la «Puna de Atacama» — cordilleras al oriente de San Pedro de Atacama - comenzaron a

17 Cámara de Diputados, L.O. 7 de junio de 1888.

18 Agradezco a nuestro amigo el diplomático boliviano Dr. Ramiro Oria la información respectiva. En la sesión de 7 de junio de 1888, el diputado Carlos Walker Martínez había prefigurado una situación en tal sentido: «Bolivia protestará sin duda de este lei, i yo sé que ya ha habido gestiones diplomáticas a este propósito».

La protesta se originó una vez que la votación favorable en el Senado a la creación de la provincia de Antofagasta de 12 de enero de 1887 trascendiera a la prensa. El diplomático boliviano acreditado en Santiago, Melchor Terrazas, enterado de la noticia, «formuló el 14 del mismo mes (enero) una terminante reclamación, aduciendo que su articulado burlaba el statu quo existente al 4 de abril de 1884, que regía las relaciones de los dos países». Cf. Espinosa Moraga, 1958: 34 .

19 Así lo afirmaba un ilustrado prelado e historiador chileno, monseñor Luis Silva Lezaeta, que sirvió como Vicario Apostólico desde 1883 hasta constituirse en el primer obispo de la diócesis de Antofagasta en 1928: «La provincia de Antofagasta fue quitada el año 1879 por Chile a la República de Bolivia, pero casi todos sus habitantes son chilenos; mas como fue segregada de un Arzobispo de Bolivia, hasta hoy el Santo Padre, por no herir susceptibilidades, mantiene a esa provincia en la parte eclesiástica con el título de Vicariato Apostólico y soy yo el que desempeño este puesto con el título de Obispo titular de Oleno. De modo, pues, que esta provincia no es Vicariato Apostólico por tener población indígena, pues todos sus habitantes son civilizados y cristianos, sino por la circunstancia ya indicada». Carta de Silva Lezaeta a la Superiora General de las Hermanas de la Caridad Cristiana, 3 de junio de 1914. Archivo del Arzobispado de Antofagasta (A.A.A.), Libro V Copiador de Oficios, años 1912-1919, Oficio n. ${ }^{\circ} 69$.

El tema jurisdiccional en lo eclesiástico entre el arzobispado de Sucre (Bolivia) y el obispado de la Serena (Chile) respecto a la asistencia espiritual en el desierto de Atacama, por medio de los capellanes castrenses chilenos, ha sido prolijamente estudiada por González Errázuriz, 1996: 41-52.

20 Vid. Alejandro Bertrand, 1885. 
MAPA OFICIAL DE LA PROVINCIA DE ANTOFAGASTA HACIA 1895

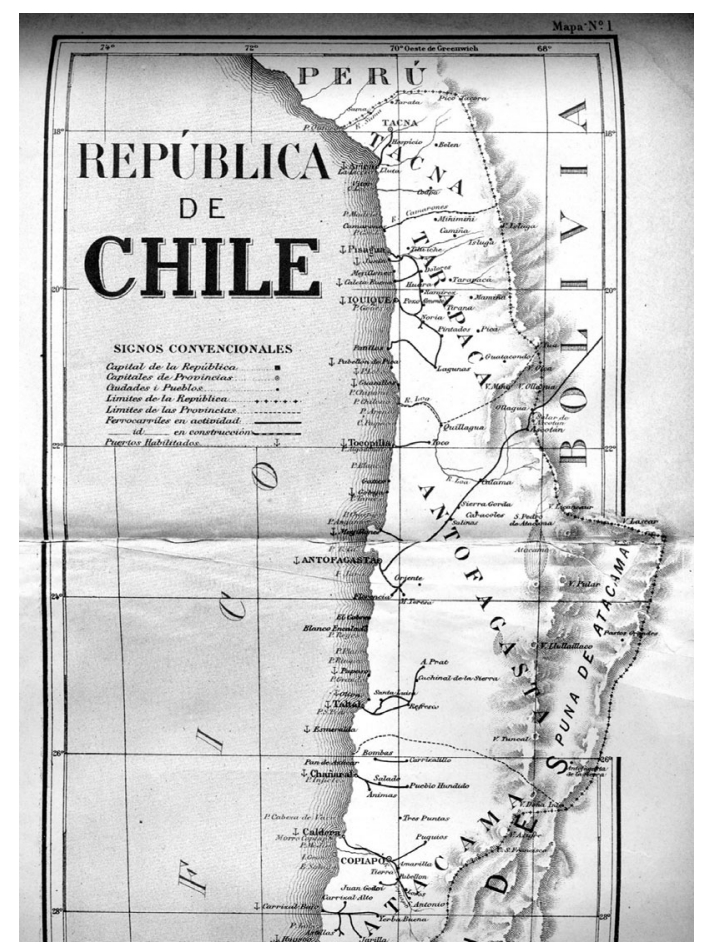

Fuente: Enrique Espinoza, 1903: Mapa 1, entre páginas 12-13.

ser atendidas, por los sacerdotes con asiento en San Pedro de Atacama, entre otras, Toconao, Socaire, Peine, Tilomonte, Rosario, Susques, Catúa, Pastos Grandes, Incahuasi, Antofagasta de la Sierra ${ }^{21}$.

Entretanto, el gobierno de Bolivia dictó una ley de 13 de noviembre de 1886, donde se incluía dentro de la provincia de Sud Lípez, las localidades de Pastos Grandes, Antofagasta de la Sierra y Carachipampa, infringiendo, anota Espinosa Moraga, «abiertamente lo dispuesto por el artículo 2 del Pacto de Tregua, ya que estando al Sur del paralelo $23^{\circ}$, estaban en poder de Chile» ${ }^{22}$. Finalmente, Argentina y Bolivia concluyeron el Tratado de 10 de mayo de 1889 donde Bolivia se quedó con Tarija y Argentina con la Puna de Atacama. Chile debió entablar conversaciones diplomáticas con Argentina.

21 González Pizarro, 2002: 61.

22 Espinosa Moraga, 1958: 29. Bolivia y Argentina tenían una disputa sobre el territorio en cuestión. 
El tema fue abordado por Chile y Argentina, desde la perspectiva geoeconómica y geopolítica respectivamente, sin importar seriamente a ambos estados las poblaciones indígenas asentadas por siglos en este territorio que era considerado periférico y marginal. En 1893 se establecieron las comunas de Calama y Caracoles, dependiendo de esta última la subdelegación de San Pedro de Atacama ${ }^{23}$. Sin embargo, en las negociaciones entre Argentina y Chile respecto de la «Puna de Atacama» hacia fines de la década de 1890, se impuso la indicación del Enviado Extraordinario y ministro Plenipotenciario de los EE.UU. en Argentina, Mr. Williams J. Buchanan, en marzo de 1899, con lo cual Chile perdió parte del sector oriental de la Puna de Atacama ${ }^{24}$. Esto afectó a la demarcación de la naciente provincia de Antofagasta y de paso a la jurisdicción eclesiástica en la precordillera andina ${ }^{25}$.

Acotemos que Chile y Bolivia firmaron el 20 de octubre de 1904 el Tratado de Paz y Amistad, que ratificó la incorporación definitiva del territorio del desierto de Atacama a Chile.

\section{EL TERRITORIO ANALIZADO DESDE LA PERSPECTIVA NACIONAL}

El territorio nacional heredó los criterios que consideró la Corona española para el ordenamiento político-administrativo del territorio ${ }^{26}$. Pero, también se acogió en el debate de la estructuración del espacio nacional, las ideas preconizadas por la Revolución Francesa, en cuanto a la departamentalización que asumía los criterios de la racionalización administrativa, por un lado, y los factores ideológicos de la igualdad y la democracia, por otro, para erigir una re-

23 María Sanhueza Tohá, 5 (Santiago de Chile, 2001): 55-82; también el examen más amplio de M. Cecilia Sanhueza Tohá-Hans Gundermann K, 34 (San Pedro de Atacama, 2007): 113-136.

24 Para las actas respectivas, la de Buenos Aires el 24 de marzo de 1899, la de Santiago de Chile, 14 de abril de 1905, y la de Santiago de Chile, 4 de abril de 1905 (en total tres), remito al sitio web http://www.bcn.cl/lc/tinterna/index html.

Una visión de conjunto en la obra de Barros van Buren (supra nota 7) y más detallada en la citada de Óscar Espinosa Moraga. Importante son las observaciones de Alejandro Benedetti, VII/2 (Iquique, 2005): 155-183.

25 Como refiere José M. Casassas, 1967: 37, «después del acuerdo a que llegaron Chile y la república Argentina, en 1899, sobre la Puna de Atacama, fue segregada de la Parroquia de San Pedro de Atacama, por resolución de la Santa Sede de fecha 2 de septiembre de 1902, la parte del territorio de la Puna o de la "Gobernación de los Andes" que, en el orden político, había pasado a dominio del vecino país, la cual pasó a corresponder desde entonces a la jurisdicción eclesiástica del Obispado de Salta».

26 Véase María Teresa Cobos Noriega, 1989. 
pública asentada en la soberanía popular. Como lo ha expuesto María Carolina Sanhueza, estas ideas foráneas - las francesas - motivaron fuertes debates entre los partidarios de las provincias y los de los departamentos, donde estos últimos habían logrado imponer sus orientaciones en el Reglamento Orgánico y Acta de Unión del pueblo de Chile de 30 de marzo de 1823. El citado texto aunaba los aspectos de la fragmentación territorial y la representación política. Durante los años 1823 a 1826 hubo confusión - e incluso disonancia entre las constituciones políticas y los proyectos de leyes - para referirse al ordenamiento territorial, pues se habló de departamentos, provincias e intendencias, «otorgándoles el mismo significado» ${ }^{27}$.

Cuando el Congreso Nacional sancionó el 29 de agosto de 1826 la división política en ocho provincias, la provincia más septentrional de Chile, llamada de Coquimbo con capital La Serena, tuvo por límites desde el despoblado de Atacama hasta la orilla norte del río Choapa. El 31 de octubre de 1843 nacía la provincia de Atacama, compuesta de los departamentos de Copiapó, Vallenar y Freirina, teniendo por capital Copiapó.

Posteriormente, se fueron incorporando nuevas provincias a medida que se consolidaban antiguos espacios. Múltiples factores políticos, militares, económicos se dieron cita para dar fisonomía político-administrativa a estos nuevos espacios. El norte grande, Tarapacá y Antofagasta, siguió el mismo derrotero. Para los antofagastinos, la idea de articular el territorio del desierto de Atacama debía comprender tres áreas, organizadas a nivel departamental, Tocopilla, Caracoles y Antofagasta. Gravitaba en ello la actividad minera en cada uno de estos sectores. Se pensaba que Taltal podía ser incorporado, precisamente, por su industria salitrera y, de este modo, armonizar la población y sus recursos productivos: todos vinculados con la minería.

Los territorios que Chile va a reivindicar y/o anexionar en el transcurso de la guerra del Pacífico, y, que finalmente, va a integrar definitivamente a su soberanía, como Tarapacá y Antofagasta (momentáneamente Tacna), serán parte del proceso de articulación de su espacio nacional. Para algunos autores, fue el inicio de la última sub-etapa que abarcó la fase de 1812 hasta 1940, es decir, desde 1884 hasta 1940, cuando se creó la provincia de Osorno. De este modo, Chile contará con 25 provincias hasta el año 1974 cuando se implementó el proceso de regionalización, transformando las provincias en regiones y los departamentos en provincias, sin variar las demarcaciones interiores establecidas antes de $1974^{28}$.

27 María Carolina Sanhueza, II/41 (Santiago de Chile, 2008): 463, nota 52.

28 José Ignacio González Leiva y Rafael Sagredo Baeza, 2005: 345-355. Agradezco al Dr. Sagredo Baeza el conocimiento de esta ponencia. 
La complejidad de la cuestión llevó al gobierno de Santiago a establecer en enero de 1884 la división de los departamentos de Copiapó y Caldera en tres: Taltal, Chañaral y Copiapó. Taltal, correspondería al límite más septentrional de la provincia de Atacama. Este nuevo departamento obligó a plantearse una visión más global por parte de las esferas gubernamentales del territorio del desierto de Atacama, que incluía a Taltal.

La misma ley que creó la provincia de Tarapacá dispuso, en su artículo 4 transitorio, que el territorio de Antofagasta a efectos de la ley electoral, se considerara como un departamento, eligiendo municipio y diputado y concurrirá con la provincia de Atacama a la elección de senadores de dicha provincia ${ }^{29}$. En consecuencia, los antofagastinos eligieron como senador a Joaquín Rodríguez Rozas, para el periodo 1885-1891. Como diputado por Antofagasta a Vicente Dávila Larraín como propietario electo, el que optó por Concepción y Talcahuano y, en consecuencia el suplente electo D. Nicolás Peña Vicuña quedó como propietario. El puerto de Taltal eligió como propietario electo a D. Manuel José Vicuña, el que se incorporó el 3 de diciembre de 1885, siendo suplente D. Vicente $\mathrm{Grez}^{30}$. La solución planteada por el gobierno no satisfizo a los habitantes de Antofagasta, pues consideraban fundamental su propia representación senatorial.

La discusión de los artículos del proyecto de ley en cuestión abrió la atención sobre otras materias que merecieron ser vistas con mayor detenimiento. Entre estos asuntos, tres concentraron las intervenciones parlamentarias: 1) si era necesario crear más provincias o dejar las cosas a nivel departamental; 2) cuál iba a ser la dependencia jurisdiccional de la administración de justicia en el desierto de Atacama y 3) cómo se iba a determinar el espacio provincial, a falta de un mayor conocimiento geográfico del área, y su denominación en la organización político administrativa nacional. Este cúmulo de temas no fue obstáculo para que gran parte de los 18 artículos del proyecto fueran despachados sin mayor discusión. El artículo 18 - que fue aprobado sin debate-indicaba que la ley entraría a regir treinta días después de su publicación en el Diario Oficial.

La intervención del diputado de Taltal, Vicente Grez apuntó a igualar los sueldos en el territorio. El Gobernador de Taltal ganaría lo mismo que el de Tocopilla, lo que fue aprobado. La sanción del proyecto dejó a la provincia de Antofagasta dividida en tres departamentos Tocopilla, Antofagasta y Taltal. La fórmula que acogió la Cámara de Diputados fue la propuesta por el ministro

${ }^{29}$ Ley 2.261, de 31 de octubre de 1884, artículo transitorio 4, en Ricardo Anguita, 1912, tomo II: 629-630.

30 Luis Valencia Avaria, 1986: 312 y 302 respectivamente. 
de Relaciones Exteriores. El Senado acogió las modificaciones introducidas por la Cámara de Diputados el 11 de julio ${ }^{31}$.

La discusión en torno a la necesidad o no de más provincias en el territorio nacional giró sobre el mayor gasto fiscal que demandaría, como ser Antofagasta, con la designación de autoridades superiores al Gobernador que ya existía desde fines de 1879. El ministro del Interior, Pedro Lucio Cuadra, en su presentación ante la Cámara de Diputados, de 9 de julio, vinculó el aumento salarial a las nuevas responsabilidades políticas. A estas dificultades, renta exigua, carestía de la vida, se vino añadir otro antecedente que puso a contraluz las condiciones de las subdelegaciones en el centro y sur del país respecto a las situadas en el norte: la inmensa distancia que separaba a las cabezas departamentales de las subdelegaciones. El diputado Julio Bañados Espinosa planteó el asunto con claridad, sosteniendo que los subdelegados en general «no tienen gran trabajo, son miembros, por decirlo así, pasivos de la administración pública» y por ende no susceptibles a mayores rentas; aunque había excepciones a esta regla general donde se incluía la zona norte del país, la provincia de Atacama y la de Antofagasta, dado que «los distritos de Calama, San Pedro de Atacama i Caracoles (poseen) idénticas condiciones a Tamaya» deberían tener equiparados sus sueldos los subdelegados.

En este contexto, se hizo notar por Carlos Walker Martínez lo innecesario de crear la subdelegación de Cobija, por su escasa población (el censo de 1885 arrojaba 1.200 habitantes y en la actualidad contaba con 600 personas), la industria y el comercio habían desaparecido. Reforzando tal planteamiento, el diputado Juan Domingo Dávila Larraín, expuso el contraste con lo apreciado en las subdelegaciones de Caracoles, Calama y San Pedro de Atacama, que «tienen una numerosa población, tienen un activo comercio i necesitan tener una autoridad administrativa de cierto prestijio»».

Desde fines de 1885 la Gobernación del Litoral Norte había hecho notar la completa desorganización existente al norte del paralelo $23^{\circ}$, que afectaba las localidades de Cobija, Calama, Chiu-Chiu y San Pedro de Atacama ${ }^{32}$. La ley que creó la provincia de Antofagasta determinó las circunscripciones del Registro Civil en los respectivos departamentos. En cuanto al tema de las municipalidades, la aprobación del artículo 13, en la sesión de 9 de junio de 1888, significó que el Presidente de la República nombraría los alcaldes del departamento de Tocopilla y en las subdelegaciones de Calama y Caracoles. El artícu1888.

31 Cámara de Diputados, L.O. 12 de julio de 1888. Ofício del Senado de 11 de julio de

32 Oficio n. ${ }^{\circ}$ 497, de la Gobernación del Litoral Norte, Antofagasta, 14 de diciembre de 1885. Archivo Nacional (A.N.), Archivo del Ministerio del Interior (A.M.I.), volumen 1320. 
lo 14 que declaraba que los terrenos urbanos que poseían las corporaciones municipales bolivianas en los territorios a que se refería la ley, han sido y continuarán siendo propiedad de dichas corporaciones, recibió la oposición de Carlos Walker Martínez por las mismas razones con las que se opuso a la redacción del artículo 1 del proyecto de ley de la provincia de Antofagasta.

A la postura del diputado Walter Martínez, se agregó la de Ricardo Letelier, que solicitó suprimir el artículo:

Consigna el artículo un principio de jurisprudencia perfectamente erróneo. ¿Qué significa esto de reconocer personería jurídica a las «corporaciones municipales bolivianas»? Estas no son comparaciones reconocidas por la lei chilena. Si estos territorios están sometidos por el tratado a las leyes chilenas ¿para qué reconocer en esta lei estas corporaciones bolivianas? Esto no puede reconocerse. Si después de ajustado el Tratado de Paz vuelven esos territorios al dominio de Bolivia, es evidente que será entonces cuando se sujetarán a las leyes bolivianas ${ }^{33}$.

El tema se zanjó con una nueva redacción del artículo 14:

Los bienes, derechos i acciones que correspondían a las corporaciones municipales bolivianas correrán a cargo de las municipalidades o juntas de alcaldes establecidas por lei de 2 de mayo de 1879 i por la presente ${ }^{34}$.

A esto se agregaba que el territorio no llenaba los requisitos demográficos para elegir un Senador, si se consideraba la exclusión de Taltal; además, quedaba de manifiesto que para suplir esto era necesario revisar lo estipulado sobre la provincia de Atacama. Y así se hizo. Lo correspondiente al departamento de Taltal quedó contenido en los artículos 2, 5, 10,15 de la ley 3.346. La organización judicial de la provincia motivó una álgida discusión en el Congreso. El debate fue iniciado en la sesión del 17 de julio de 1888 por el diputado Juan E. Mackenna, representante de Valparaíso, quien solicitó activar el proyecto de creación de la Corte de Apelaciones en Valparaíso y la supresión de la Corte de Apelaciones de Tacna. En el principal puerto chileno - sostuvo- estaban las principales casas comerciales nacionales y extranjeras, «allí se negocian los salitres de Tarapacá» y, en consecuencia, en «Valparaíso conviene a todos tener el asiento de la Corte de Apelaciones, donde sus intereses están relacionados i sus litigios pueden ser bien atendidos». La jurisdicción de la Corte de Valparaíso debía alcanzar hasta Tacna ${ }^{35}$. Para Mackenna, todo el «mundo viajaba entre Valparaíso y Tarapacá por los intereses habidos nadie a

33 Cámara de Diputados, L.O. 9 de julio de 1888.

34 Ley 3.346 de 13 de julio de 1888 que crea la provincia de Antofagasta, en Ricardo Anguita, 1912, tomo III: 75.

35 Cámara de Diputados, L.O. 17 de julio de 1888. 
Tacna». De paso se cuestionó severamente los procedimientos observados en el Poder Judicial de Iquique ${ }^{36}$.

¿Por qué la mencionada discusión afectaba a la naciente provincia de Antofagasta? La ley 2.469 de 17 de julio de 1885 había creado el distrito jurisdiccional del Juzgado de Letras de Antofagasta. Allí se señalaba que las causas que habían tenido origen «entre la márjen sur del río Loa paralelo $23^{\circ}$ de latitud sur» y fueran apeladas o en consulta, serían falladas por la Corte de Apelaciones de Iquique; y la Corte de Apelaciones de la Serena conocerá todas las causas remitidas por el Juzgado de Letras de Antofagasta. Si se suprimía la Corte de Apelaciones de Iquique, ¿cuál iba a ser la situación del Juzgado de Letras de Antofagasta? ¿Debía depender exclusivamente de la Corte de Apelaciones de la Serena? Para el diputado Enrique Mac Iver era imprescindible — exclamaba en la sesión de 17 de julio de 1888 - determinar dónde iba a quedar la Corte de Apelaciones: en Iquique o Tacna o en cualquier lugar del territorio nacional. La intervención guardaba relación con su argumentación del 9 de junio donde, en base a criterios de mayor eficiencia, competitividad y familiaridad en los asuntos ventilados, había sostenido:

¿Qué tiene que ver un salitrero de Antofagasta con la Corte de la Serena? Pero sí tiene mucho que ver con la Corte de Tarapacá, porque sus intereses están en íntima relación con la índole i naturaleza de aquel territorio ${ }^{37}$.

El artículo 11 del proyecto de creación de la provincia de Antofagasta señalaba que los juzgados de Antofagasta y Taltal iban a depender de la Corte de Apelaciones de Iquique y la Corte de Apelaciones de la Serena iba a continuar conociendo en las causas que, habiendo tenido origen en el juzgado de Taltal, le hubieran sido enviadas en apelación o consulta. En la sesión de 9 de julio, el ministro de Justicia Puga Borne formuló una indicación para sustituir el contenido del artículo 11 por otro que señalaba que los Juzgados de Letras de la provincia dependerán de la Corte de Apelaciones de La Serena. Y esto, argumentaba el ministro de Justicia, por estar pendiente la supresión o traslado de la Corte de Tacna (o Iquique) y la «mayor proximidad de esos departamentos (Antofagasta y Taltal) a la Corte de la Serena». Para el diputado Ricardo Lete-

36 El diputado Mackenna llamaba la atención que el «propio Presidente de la República, D. J. M. Balmaceda, en su Mensaje de 1 de junio de 1887 al Congreso Nacional manifestaba que la «Corte de Apelaciones de Iquique, ahora en Tacna, no ha correspondido a los fines para que fue creada. El Presidente de la República, en el Mensaje de 1 de junio de 1887 al Congreso Nacional, dice que es urgente la necesidad de ocuparse del proyecto que suprime la Corte de Tacna i crea una nueva en Valparaíso». Cámara de Diputados, L.O. 7 de agosto de 1888. Destacados en el texto.

37 Cámara de Diputados, L.O. 9 de junio de 1888. 
lier había que modificar algunos contenidos del proyecto, pues de quién dependerían los oficiales del Registro Civil, los jueces de subdelegación y los demás empleados judiciales.

El Congreso hizo caso omiso a la indicación del ministro de Justicia y resolvió que el artículo 11 fuese aprobado con el texto que declaraba que el departamento de Taltal continuaba bajo la jurisdicción de la Corte de la Serena y los de Tocopilla y Antofagasta bajo la de Tacna. Indiquemos que durante la guerra civil de 1891, la Junta de Gobierno, con asiento en Iquique, decretó el 9 de julio que la provincia de Atacama y el departamento de Taltal se agregaban al territorio jurisdiccional de la Corte de Apelaciones de Iquique.

Un último tema fue lo concerniente al conocimiento que se poseía del territorio de la provincia de Antofagasta. En el transcurso de la sesión de 7 de junio de 1888, el diputado por Linares, Julio Zegers, cuestionó que el proyecto de ley de la provincia de Antofagasta se remitiese a otra ley, en cuanto a sus límites sur y oriente. Julio Bañados Espinosa, miembro de la Comisión de Gobierno, contestó que para la fijación de los límites «se consultó a la Oficina Hidrográfica i al ingeniero señor San Román, conocedor de aquellas localidades». En su oportunidad, los vecinos de Antofagasta formularon sus ideas sobre la organización del territorio ${ }^{38}$.

Desde el año 1881 la ciudad comenzó a debatir la organización político-administrativa del territorio. Rojas Delgado, fustigó con sorna sobre lo que se estaba realizando a espaldas de los intereses y sentimientos regionales:

No se le ocurrió a ningún Senador ni a ningún Diputado acordarse de la organización del territorio i el Ministro creyendo haber salido del paso relegó al olvido lo que en un momento dado tanto le preocupó, entregando la resolución de tan importante asunto a una Comisión compuesta de personas que conocen tanto estos lugares como nosotros al Japón ${ }^{39}$.

Un primer boceto de división territorial fue realizado por Salvador Reyes. Éste consistió en determinar cuatro departamentos: Tocopilla, Antofagasta, Caracoles y San Pedro de Atacama. Tocopilla estaría dividido en dos subdelegaciones. El departamento de Antofagasta estaría dividido en siete subdelegaciones. El departamento de Caracoles comprendía tres subdelegaciones y el departamento de San Pedro de Atacama dos subdelegaciones ${ }^{40}$.

Contemporáneamente a la propuesta de Salvador Reyes, se encomendó por el ministerio de Guerra y Marina al capitán de fragata Francisco Vidal Gormaz

38 Matías Rojas Delgado, 1883: 145-152.

39 Matías Rojas Delgado, 1883: 135-136.

40 Salvador Reyes, Proyecto de división territorial en subdelegaciones $i$ distritos de la provincia de Antofagasta, Antofagasta, 31 de mayo de 1881. A.N., A.M.I., vol. 869. 
estudiar el litoral de Tarapacá, pero debido a las acciones militares se concentró en Iquique y en Antofagasta. En esta última localidad permaneció cerca de un mes lo que, «le permitió fijar las coordenadas geográficas de este puerto con bastante precisión ${ }^{41}$. Para Vidal Gormaz, el paraje no le era desconocido. Había redactado su notable Jeografía Nautica de Bolivia dando a conocer las localidades que ahora Chile reivindicaba o bien ocupaba. En marzo de 1879 Vidal Gormaz acometió la redacción de las Noticias del desierto i sus recursos. Durante el año 1881 emprendió su «Memorándum» sobre la organización de la provincia de Antofagasta. En honor al combate que había destruido el poderío naval peruano sugirió como denominación para la provincia la de «Angamos».

El territorio debía abarcar la provincia boliviana del Litoral, los territorios de la jurisdicción de San Pedro de Atacama, los territorios reivindicados situados al sur del grado 23 e incorporados legalmente a Chile; además, añadir los territorios comprendidos entre el grado 24 y el $241 / 2$ que pertenecían a la provincia de Atacama. Es interesante la argumentación que se lee en el Memorándum:

La razón de esta segregación se funda en que entre esos paralelos están comprendidos las salitreras de Aguas Blancas, los minerales El Cobre, Blanco Encalada todos los que, por su proximidad a Antofagasta, son i deben ser atendidos desde este puerto. Las salitreras de Aguas Blancas sobre todo tienen hoy todo su tráfico de introducción i de retorno por Antofagasta, único puerto de salida para sus productos i única vía proyectada i estudiada para un ferrocarril a las salitreras. Actualmente estas salitreras están en la jurisdicción del departamento de Copiapó i sin más comunicaciones con este que la vía marítima de Antofagasta a Caldera i a Copiapó. No se escapará a U.S. los gravísimos inconvenientes judiciales, administrativos e industriales nacidos de tal estado de cosas i la evidente utilidad que presenta la división que proponemos ${ }^{42}$.

En consecuencia, era prudente y racional dividir el territorio en tres departamentos: el de Tocopilla, basándose en los mapas peruanos y bolivianos; el de Caracoles, el que agrupa la región minera de la provincia; el de Antofagasta, la región salitrera incluida la de Aguas Blancas, pero excluida las salitreras del Toco, más inmediata a la localidad de Tocopilla; y el departamento de Angamos, que comprendería «todos los valles i vertientes que converjen a la laguna de Atacama, incluso los pueblos de San Pedro, Toconao, San Bartolo, etc.».

41 Anuario, 7 (Santiago de Chile, 1881): VI.

42 Oficina Hidrográfica de Chile, Memorándum sobre la nueva provincia de Angamos de Joaquin Santalmos y Francisco Vidal Gormaz. A.N., A.M.I., volumen 869. El documento está sin datar y se localiza entre papeles de 1881 y 1883 . Nos inclinamos en fecharlo en 1881 por las razones aducidas en el texto. 
El informe sugería algunas medidas, como encargar a una comisión local en cada departamento la fijación de la línea definitiva de deslinde de cada departamento; que las autoridades propongan «un plan de división racional de los departamentos citados en subdelegaciones i distritos»y, finalmente, encargar a una comisión de científicos que acompañe a las comisiones locales a fin de «hacer los estudios que esas regiones, casi desconocidas, exigen». El 13 de julio de 1888, se promulgaba por el Presidente de la República la ley 3.346, que creaba la provincia de Antofagasta. Una vez en vigor la ley respectiva, el municipio de Antofagasta hizo llegar algunas ideas sobre la organización del departamento de Antofagasta ${ }^{43}$.

\section{El TERRITORIO DE ANTOFAGASTA: CONSOLIDACIÓN Y DIVISIONES INTERNAS EN LA PRIMERA MITAD DEL SIGLO XX}

Importa ahora detenernos en revisar la evolución interna del territorio en la perspectiva del cambio del eje del régimen político nacional y las nuevas demandas procedentes de las realidades socio-económicas que mostraban los departamentos de la provincia de Antofagasta.

En los primeros lustros del siglo XX se procuró tender a buscar una mayor descentralización administrativa. La bancada del Partido Radical había abogado desde su programa de 1888 por las Asambleas Provinciales. El Congreso debatió en las tres primeras décadas del siglo XX diversos proyectos de descentralización que afectaban a las provincias del Norte Grande (Tarapacá y Antofagasta) como fueron los de Ramón Briones en 1916, de Alberto Edwards en 1919 y los Senadores Conservadores en 1924. Los proyectos no prosperaron. Las demandas por procurar un reconocimiento político-jurídico de algunas áreas de la provincia de Antofagasta, como ser la faja oriental que albergaba a Calama y los poblados precordilleranos, se hicieron notar con mayor fuerza en la década de 1900.

Los diputados por Antofagasta, Taltal y Tocopilla, señores Lindorfo Alarcón y Eduardo Délano, lograron acordar una presentación al gobierno solicitando la creación del departamento de El Loa. La administración de Pedro Montt acogió la petición y presentó un proyecto de ley en tal sentido a la Cá-

43 Véase Provincia de Antofagasta. División administrativa del Departamento de Antofagasta, informe de la Comisión especial, Antofagasta, 5 de setiembre de 1888. Archivo Municipal de Antofagasta (A.M.A.), Libro de Actas Municipales años 1885 a 1889, sesión de 5 de setiembre de 1888, ffss 271-276. 
mara de Diputados, en agosto de 1909. Importa destacar los fundamentos de la división en cuestión:

La ciudad de Calama, por ejemplo, dista de Antofagasta tanto como la de Talca de la de Santiago. Con la parte oriente se puede formar el departamento de El Loa, que tendría una superficie de sesenta i cinco cuatrocientos sesenta kilómetros i una población de veintidós mil sesenta i nueve habitantes, quedando el de Antofagasta con una superficie de veintiun mil novecientos noventa kilómetros cuadrados i una población de cuarenta i siete mil ochocientos noventa i cuatro habitantes ${ }^{44}$.

El proyecto de ley quedó durmiendo meses en el Congreso. La dificultad mayor estribó que al fijarse el límite sur del departamento de El Loa, Antofagasta perdía toda la zona salitrera, quedando reducida a su actividad comercial y portuaria. Motivo suficiente para que la Comisión de Gobierno dilatara su pronunciamiento y finalmente no prosperara la iniciativa lega ${ }^{45}$. La estrecha vinculación entre el mundo minero de la depresión intermedia del desierto y los asentamientos humanos de cierta categoría - reflejada en lo administrativo- quedó nuevamente demostrado, por los abruptos cambios que sobrevinieron con las constantes crisis de la industria salitrera y de la minería menor de la zona.

El 30 de noviembre de 1917, por la ley 3.326, se agregó a la municipalidad de Antofagasta la comuna de Caracoles, obligando al ayuntamiento costero socorrer a los reductos poblacionales tanto de Caracoles como de Sierra Gorda. El más significativo cambio se logró por la decisión de la entonces Junta de Gobierno, del general Luis Altamirano, el almirante Francisco Nef y el general Juan P. Bennett, que, mediante el D.L. 75 de 31 de octubre de 1924, creó el departamento El Loa. Es sorprendente que en los considerandos de la normativa se trasluzca todavía el impreciso conocimiento del territorio del departamento de Antofagasta. Si en el proyecto de ley de 1909 se hacía constar una superficie de $87.450 \mathrm{kms}^{2}$; en 1924 se reducía a 85.650 $\mathrm{kms}^{2}$. Un antecedente mayor era el aumento considerable de la población «en la región oriente de la provincia debido al auge de las industrias extractivas y fabriles $»^{46}$.

44 Proyecto de lei (departamento El Loa), Santiago, 23 de agosto de 1909, Cámara de Diputados, L.O. 26 de agosto de 1909.

45 Algunos parlamentarios solicitaron agilizar el informe de la mentada Comisión para decidir rápidamente la cuestión, como el diputado Ascanio Bascuñán, Presidente de la Corporación, y el diputado por San Fernando, José María Bustos. Cf. Cámara de Diputados, L.E. Sesiones 13 de diciembre de 1909 y 19 de enero de 1910.

46 Ministerio del Interior D.L. . $^{\circ}$ 75, Excma. Junta de Gobierno, Santiago, 31 de octubre de 1924, A.N., Archivo de la Intendencia de Antofagasta (A.I.A.), volumen 35. 
La ciudad de Calama quedaba como capital del departamento de El Loa. Era palmario que la creciente importancia del mineral de cobre de Chuquicamata, que estaba en funcionamiento desde la década anterior hizo posible la nueva división político-administrativa, más allá del mecanismo empleado para erigirla. Aquello supuso concretar las modificaciones de los departamentos de Tocopilla y Antofagasta, de acuerdo al tenor de su artículo 3:

El territorio del actual departamento de Antofagasta, que queda entre el límite poniente del departamento de El Loa y el río del mismo nombre, se agregará al departamento de Tocopilla; y el comprendido entre el límite norte del departamento El Loa y el actual límite sur de Tarapacá, quedará anexado a este último.

La Junta Militar postergó — «será fijado oportunamente»— el número y límites de las subdelegaciones respectivas de los departamentos ${ }^{47}$. Otra norma, el D.L. n. ${ }^{\circ}$ 354, de 17 de marzo de 1925, vino a precisar los límites de los departamentos de toda la República, manteniéndose los correspondientes a los departamentos de Tocopilla, El Loa, Antofagasta, Taltal ${ }^{48}$. Consignemos que las constantes modificaciones administrativas en el territorio acarrearon más de una controversia jurisdiccional entre las Intendencias de Tarapacá y Antofagasta ${ }^{49}$. De esta manera quedaba claramente señalado el influjo minero en las nuevas divisiones administrativas. En la última década del siglo XIX, por ley 317 bis, de 16 de diciembre de 1895, se había suprimido la comuna El Toco e integrado en la comuna de Tocopilla. La misma disposición indicó la supresión de la comuna Caleta Buena y su incorporación a la de Iquique. El 17 de junio de 1926 se fundaba el pueblo de Baquedano, en el límite sur del cantón salitrero central, en la jurisdicción del departamento de Antofagasta.

47 La Municipalidad de Calama solicitó en abril de 1925 al Presidente de la República, al ministro del Interior y al Intendente provincial, que se agilizara el nombramiento de las autoridades para el nuevo departamento. Archivo de la Municipalidad de Calama, Volumen 8 de Actas Municipales, sesiones ordinarias de 8 y 21 de abril de 1925.

El gobernador de Calama designó el 2 de julio de 1925 a los subdelegados en las localidades de Calama, Chuquicamata, Ascotán y San Pedro de Atacama. A.N., A.I.A., vol. 35.

La población de Chuquicamata rápidamente hizo valer sus derechos y así, en un comicio público de 1 de febrero de 1925 , que reunió a más de 1.000 personas, solicitó a la Junta de Gobierno incrementar el número de registros electorales, el nombramiento de las autoridades correspondientes al departamento de El Loa, como Juez de Letras, Notario, etc.

48 Ministerio del Interior, D. Lei n. ${ }^{\circ} 354$, Excma. Junta de Gobierno, Santiago, 17 de marzo de 1925, pp. 2-4. En A.N., A.I.A., vol. 35. Es una norma muy poco conocida, dictada tres días antes de reasumir Arturo Alessandri Palma la Presidencia de la República.

49 Oficios del Intendente de Antofagasta, 28 de julio y 14 de agosto de 1926; Oficio del Gobernador de Calama, 5 de junio de 1926; Oficio de la Dirección de OO.PP. de la provincia de Tarapacá, 22 de julio de 1926. A.N., A.I.A., vol. 46. 
Importa destacar en esta primera mitad del siglo XX tres aspectos concomitantes con la realidad de la provincia de Antofagasta: 1. El debate producido en el seno de la Comisión Constituyente de la Constitución de 1925; 2. Los cambios ocurridos entre los años 1925 y 1926; 3. La nueva ordenación político-administrativa bajo el gobierno de Carlos Ibáñez del Campo.

Cuando se discutió la nueva Constitución Política en 1925 se puso de manifiesto la disconformidad con el régimen interior de la República. Es interesante constatar cómo algunos planteamientos que observáramos en el siglo XIX sobre la funcionalidad del ordenamiento territorial fueron esgrimidos para dar una solución integral sobre la materia: uno, que la «actual división en provincias no significa nada, ni responde a ningún objeto preciso y útil», como expuso Héctor Zañartu. Si se deseaba buscar una descentralización administrativa lo conveniente era crear grandes provincias. Dos, si la elección de los Senadores iba a estar vinculada con el número de población. La idea era contar con diez agrupaciones y cada una elegiría cuatro senadores; mientras las provincias serían nueve ${ }^{50}$. Antofagasta comprendería los departamentos de Tacna, Arica, Pisagua, Iquique, El Loa, Tocopilla, Antofagasta y Taltal, teniendo como capital a Iquique.

Se asignó una importancia crucial en el proyecto de Zañartu al papel de las Asambleas Provinciales, compuesta de miembros - ciudadanos y naturales de la provincia o avecindados en ella - elegidos cada tres años por votación popular directa, que tendría facultades de fijar los límites de las poblaciones para los efectos de la elección de la Municipalidad, el número y límite de las circunscripciones comunales en que debe dividirse cada departamento y autorizar la construcción de ferrocarriles particulares, puentes, caminos, dictar ordenanzas de aplicación general en la provincia. Un cuestionamiento incisivo provino de J. Guillermo Guerra que expuso que la creación de la primera agrupación, con las provincias de Tacna, Tarapacá y Antofagasta, no presentaba una coherencia ni poblacional ni productiva: «Tacna es agrícola, Tarapacá y Antofagasta son salitreras y mineras. Hay una diversidad muy grande de actividades entre la una y las otras $\rangle^{51}$. Se buscaba, en palabras de Alessandri, que los senadores representaran a la región, al país, por lo que el factor poblacional estaba contemplado para los diputados. Para el Presidente de la República era procurar una división en «diez grandes zonas, según sus características: la zona minera, la zona agrícola, etc.». El tema no era tan simple en la conjunción territorial y representación política. Para Manuel Hidalgo, representante

50 Cf. Ministerio del Interior, 1925: 165-171. Décimocuarta sesión de la subcomisión de reformas constitucionales. La indicación fue rechazada.

51 Ministerio del Interior, 1925: 178. 
del Partido Comunista, tales agrupaciones provinciales eliminarían a los partidos pequeños. Su preocupación sin duda reflejaba que donde más fortaleza política tenía su agrupación partidaria —el Norte Grande, Tarapacá y Antofagasta - con el nuevo ordenamiento quedarían sólo las grandes conformaciones políticas tradicionales.

Otro de los temas atingentes a las provincias fue la de estampar en la Carta fundamental la división en provincias y departamentos, «dejando a la ley la subdivisión en comunas, subdelegaciones y distritos», como fue la acotación de Carlos Vicuña Fuentes ${ }^{52}$. El debate sobre las autoridades provinciales - como ser efectividad del Intendente, duración en los cargos del Intendente, Gobernador, etc.- dejó meridianamente señalado la dificultad del ordenamiento territorial con la búsqueda de mayores atribuciones al Presidente de la República. Se perseguía que el Intendente no debía gobernar asesorado por las Asambleas Provinciales sino en conformidad con las órdenes e instrucciones del Presidente de la República. En este contexto, cuando se desarrolle la sesión de la subcomisión de reformas constitucionales de 15 de junio, volvieron a escucharse las demandas por establecer grandes provincias aunadas por reunir ciertas características, como ser riqueza, población, comunidad de intereses, calidad de su producción y actividades, vías fáciles que las unan entre sí, poseer ciudades capitales con instituciones de crédito, comercio, industrias, sociabilidad y comodidad para que la vida fuese útil y agradable, etc. ${ }^{53}$.

Alessandri, que había transitado desde un entusiasmo por la descentralización a ser un partidario del centralismo administrativo, hizo presente que el país se había formado en «virtud de ciertas razones étnicas, geográficas y políticas» y por consiguiente no podía desarticularse a voluntad por medio de leyes. Y esto al tenor de conciliar la idea de las Asambleas Provinciales con la manutención de las actuales provincias.

La Constitución de 1925 promulgada el 18 de septiembre recogió en el artículo 88 que para efecto del régimen interior del Estado, el territorio se dividía en provincias, las provincias en departamentos, los departamentos en subdelegaciones y las subdelegaciones en distritos. El gobierno superior de la provincia recaía en el Intendente, asesorado por una Asamblea Provincial, compuesta por representantes designados por las Municipalidades de la provincia, los cargos serían concejiles y durarían tres años, indicaba en sus artículos 89, 94 y 95 . Destaquemos que las características de las poblaciones nortinas, esencialmente mineras, a su vez, acarrearon otras aplicaciones «adminis-

52 Ministerio del Interior, 1925: 265.

53 Ministerio del Interior, 1925: 273. 
trativas» exclusivas para las provincias de Tarapacá y Antofagasta, como fue el D.L. n. ${ }^{\circ}$ 550, de 23 de septiembre de $1925^{54}$.

La carencia de implementación de determinados servicios públicos, por un lado, y la importancia de los intereses mineros en la zona, por otro, motivaron inquietudes respecto de la dependencia jurisdiccional, principalmente de las propiedades mineras; circunstancia que fue pretexto para algunos ejecutivos de compañías mineras para representar a la autoridad provincial su parecer y proponer ideas ante los cambios introducidos. La propia historia regional - a su vez- había hecho valer tales presiones desde los inicios de la ciudad de Antofagasta y con fuerza en los momentos de mayor inflexión en el decurso de los años florecientes de la industria salitrera; ahora, era el de la industria cuprífera.

El referido D.L. n. ${ }^{\circ}$ 75, de 31 de octubre de 1924, que daba vida al departamento de El Loa, en vigencia desde el $1 .^{\circ}$ de enero de 1925, fue revisado por el gobierno de Alessandri. Tanto el nuevo ordenamiento constitucional como las exigencias políticas regionales, llevó a su administración a solicitar a las autoridades departamentales y provincial de Antofagasta cómo debería plantearse el nuevo mapa político-administrativo y qué problemas acarrearía al territorio la aplicación de la Constitución de 1925. La ocasión no fue desaprovechada por ningún sector de la sociedad regional. El ingeniero norteamericano W. A. Perkins, en marzo de 1925, le hizo saber al Intendente de Antofagasta sus aprehensiones sobre la solicitud de los habitantes de Collahuasi de incorporarse al departamento de El Loa y de paso descartar la participación de la Chile -Exploration - sugerida por la prensa local — de haber intervenido en la creación del nuevo departamento-. Para Perkins, los ejecutivos y la empresa norteamericana, habrían preferido «el centralismo o sea quedar directamente bajo la dependencia de las Autoridades Administrativas y Judiciales de Antofagasta». Y, en tal predicamento, de oposición al nuevo departamento de El Loa, dado que sus límites:

No sólo se perjudica a nuestra Compañía sino también a muchos mineros de la región que verían sus minas y propiedades no en el Departamento del Loa, que hoy

54 Esta disposición determinó la prohibición dentro de los barrios urbanos de las ciudades de Pisagua, Iquique, Antofagasta, Tocopilla y Taltal del expendio y consumo de bebidas alcohólicas, fijando para «el resto de la provincia se dividiría en zona de temperancia limitada y en zona seca», por lo cual, rezaba el artículo 5, la zona de temperancia limitada comprenderá «la ciudad de Calama, los puertos legalmente habilitados, las oficinas salitreras, el mineral de Chuquicamata» y los establecimientos mineros e industriales que el Presidente de la República considere en esta categoría; y el artículo 6, al expresar la zona seca aludía a las regiones rurales y los pueblos y caseríos no incluidos en el artículo precedente. A.N., A.I.A., vol. 35. 
en día es Antofagasta, sino trasladados al Departamento de Tocopilla o a la provincia de Tarapacá, sin objeto práctico alguno. Me parece injusto que los mineros de El Abra, El Inca, Arralar, Atahualpa, Ojo del Gallo, Paco Paco, Viscachillas, Sajasa y Yucas, tuvieran que ir a Tocopilla para ventilar sus asuntos judiciales, pagar patentes, hacer tramitación de mensura, etc., adonde no hay vías de comunicaciones... A excepción de la Compañía, los mineros de esta región son de escasos recursos, y con esta nueva creación se le ocasiona un verdadero impedimento para proseguir en sus trabajos. Además, los mineros ahora leen los diarios de Antofagasta y se mantienen al corriente de las notificaciones judiciales, remates de minas, etc., porque estos diarios circulan por todas partes del interior, ¿Cómo podrían ellos informarse fácilmente de los diarios de Tocopilla o Iquique? ${ }^{55}$.

Para Perkins, el nuevo departamento - y la fijación de los límites - obedecía a satisfacer necesidades estratégicas en lo militar, un tema muy recurrente en el lustro ${ }^{56}$, empero afectaba en materias civiles, al verse los mineros obligados a «trasladar parte de su titulación de Antofagasta a Calama» y el resto a Tocopilla. El ingeniero norteamericano adjuntó a su oficio un mapa indicativo de los nuevos límites del departamento, haciéndole ver al Intendente Arturo Acevedo, lo que sería lo ideal («en líneas quebradas he indicado en el plano una delimitación que sería ventajosa para los mineros»), y que permite entender la última interrogante sobre el asunto:

Si es que el nuevo Departamento quedare establecido ¿por qué no se había de proceder con mayor criterio al fijar los límites y de esta manera hacer de él un beneficio para los mineros que trabajan en esta región, ajustándose a la conveniencia fiscal y particular, y no a la ventura, sin conocer ni tomar en consideración los intereses en el terreno, ya que cualquier rumbo o evolución que se inicie en una región debe ser en bien de los pobladores, siempre que el Estado no sea perjudicado en ello? ${ }^{57}$.

Previamente el Intendente había oficiado al Ministerio del Interior su opinión respecto a la creación del departamento de El Loa. En su lato escrito el Intendente dividió éste en opiniones adversas y en partidarios a la creación del departamento El Loa. Los detractores al nuevo ordenamiento provincial basaban sus argumentos en los puntos siguientes:

55 Carta de W. A. Perkins, Antofagasta, 19 de marzo de 1925, al Intendente Arturo Acevedo, en A.N., A.I.A., vol. 35.

56 Una materia donde los antofagastinos habíanse interiorizado con ocasión del debate en torno a la construcción del Ferrocarril de Antofagasta a Salta y que defendieron con fuerza en los grandes comicios cívicos celebrados entre 1920 y 1923; las intervenciones militares no fueron concordantes: el general Salvador Vergara se opuso por afectar a la defensa nacional y el general Jorge Boonen Rivera apoyó la iniciativa. Cf. Gajardo Cruzat, 1924.

57 Supra nota 56. 
1. La población del departamento nuevo descansaba en la aglomeración en torno al mineral de Chuquicamata, 13.480 habitantes, siendo el resto insignificante en términos estadísticos: Calama 2.180, Borax Consolidated 1.280, Ascotán 10, Ollagüe 300, San Pedro de Atacama 350, Estación de San Pedro de Atacama, 10, Pueblo de Ayquina, Caspana y Toconce, 58, Peine 80 y Tilomonte 20. De un total de $18.418,14.760$ correspondían a obreros de la Chilex Exploration y Borax Consolidated; 2. El avalúo de la propiedad de los habitantes del departamento, dedicados al cultivo de la tierra, es «demasiado exiguo para responder a la constitución de esta división administrativa»; 3. El número de causas en la región de El Loa era muy reducido: las causas civiles y criminales sumaban 84; 4. El movimiento notarial en la región de El Loa alcanzó en 1924 a un total de 95 escrituras; 5. En lo concerniente a la instrucción pública, el número de alumnos no ameritaba un nuevo organismo administrativo. Calama, con tres escuelas, sumaba 600 alumnos, Chuquicamata, con dos escuelas superiores, 1.400 alumnos. El resto de los poblados, 130 alumnos; 6. La creación del departamento acarrearía daños y perjuicios a los civiles, siendo el más notorio el traslado de su titulación minera del Conservador de Bienes de Antofagasta al Conservador de Minas de El Loa, significando este traslado a la Chilex Exploration y a la Borax Consolidated un gasto superior a los 2 millones de pesos. Este gasto extraordinario, anotaba el informe, se agravaría pues los «tinterillos mineros» podrían aprovechar de denunciar minas en el Conservador de Minas de Calama, «que tienen titulación antigua en Antofagasta».

Los partidarios de la creación del nuevo departamento expusieron cinco razones:

1. El departamento El Loa había existido en «tiempos de la dominación boliviana y desapareció con la creación del territorio de Antofagasta». Ante esta injusticia histórica, Alessandri se había comprometido con los «habitantes del interior» por interesarse en estudiar la creación del departamento; 2. El Estado Mayor General del Ejército, en su estudio de la defensa del país, había solicitado la creación del departamento "como una necesidad nacional, reconociendo que en Calama debía haber una fuerte guarnición para cubrir dos fronteras»; 3. El aumento de la industria al interior, muy incipiente hacia 1888, había tenido una gran contribución con el mineral de Chuquicamata, y se aguardaba un importante incremento en otros rubros: fábrica de pólvora negra, explosivos de nitroglicerina, planta de luz eléctrica, gran maestranza del FF.CC. La minería boratera, azufrera, cuprífera, de mármol y de plomo estaba cobrando una importancia en la economía regional. El comercio de ganado desde Argentina era de 30.000 cabezas anuales; 4. La necesidad de implementar los servicios del Estado en la región, en los ámbitos de la administración de justicia, por el «cúmulo de abusos y atropellos» provenientes por los jueces de dis- 
trito y los de subdelegación que no podían fallar en causas superiores a 50 y 200 pesos respectivamente; empero intervenían y fallaban en juicios superiores a mil pesos. Antes de hacer el largo viaje a la costa, con los gastos de pasajes, hoteles, constituir apoderados, renunciando a la prueba testimonial, por las mismas razones, se optaba por aceptar estas transgresiones. Era la explicación del exiguo número de causas en los juzgados de Antofagasta. Además estaba la aplicación de la ley de accidentes del trabajo, «de que deben entender hoy día los jueces letrados» que era prácticamente nula, precisamente por la carencia de tales juzgados en una región esencialmente industrial donde «ocurren a diario numerosos accidentes». La justicia criminal no existía en Calama, pues los jueces inferiores, con graves defectos en los sumarios, «dejaban en la impunidad la mayor parte de los delitos, desde el asesinato hasta el robo a mano armada»; 5. La falta de Notaría, ocasionaba enormes perjuicios a los habitantes. Para cualquier acto que demandaba la presencia de un Notario (la venta de una modesta casa, una parcela de terreno, un contrato de arriendo de minas, dictar un testamento, inscribir minas o propiedades), se debía concurrir a la ciudad de Antofagasta. Concluía el Intendente que el interés político estaba comprometido con la creación del departamento, por lo que reafirmaba su opinión favorable al mantenimiento del D.L. n. ${ }^{\circ} 75$ de 31 de octubre de $1924^{58}$.

Pero no fue la única voz disonante ante los cambios establecidos. Las otras autoridades del territorio hicieron saber determinadas reservas. Incomodaba la aparición de varias comunas que no se sustentaban en el tiempo, que era el correlato del artículo 93 de la nueva Constitución, «cada territorio comunal corresponderá a una subdelegación completa». La revisión de la medida expuesta por el gobernador de Tocopilla, apuntaba a la dificultad en el desierto de Atacama de su aplicación, pues en base de tal artículo la comuna de Tocopilla debía desprenderse de la 3. ${ }^{a}$ subdelegación para observar una nueva comuna y constatar tres subdelegaciones y comunas en el territorio departamental: $1 .{ }^{\text {a }}$ Subdelegación y comuna de Tocopilla; $2 .{ }^{\text {a }}$ Subdelegación y comuna de Cobija y 3. ${ }^{a}$ Subdelegación y comuna del Toco.

La hecatombe que preveía el Gobernador se avalaba en el dato que mostraba que el $90 \%$ de las entradas del municipio de Tocopilla provenía de las salitreras del interior, las que ahora quedarían incorporadas a la 3. ${ }^{a}$ Subdelegación. De esta manera, la única ciudad de importancia, Tocopilla, quedaría afectada irremediablemente en sus ingresos fiscales. Tocopilla exhibía una sociedad organizada, comercio, industria, propiedad subdividida, instituciones de todo orden. La pampa era la antítesis, donde la artificialidad de un organismo edili-

58 Informe del Intendente de Antofagasta, 10 de marzo de 1925, al ministro del Interior. A.N., A.I.A., vol. 35. 
cio, con recursos muy superiores a sus necesidades, introduciría anarquía, rapiña y otros vicios ${ }^{59}$.

Para la autoridad de Tocopilla, como no era posible desobedecer la nueva Constitución como tampoco un desacato, visualizaba como solución legal, eficaz y conveniente «refundir en una sola las tres subdelegaciones actuales de Tocopilla» y reunir en una sola Municipalidad las dos existentes. La medida, argumentaba, no ocasionaría ningún perjuicio, pues, «lo que necesita la pampa (es) buena y constante acción de paz social, justicia para los pobres, el mínimo de bienestar reclamado por el obrero, garantías de orden, fiscalización general efectiva y honrada de parte del Estado ${ }^{60}$. Similar postura sostuvo el gobernador de Taltal, para quien debería desaparecer las comunas en asientos salitreros y ser anexadas a Taltal; se refería a las comunas de Santa Luisa y de Refresco. La primera comuna, «mantiene dos pueblos que hasta hace poco vivían de los vicios ${ }^{61}$; y respecto de la segunda, los pueblos de Refresco y Catalina, «dos antros de vicios y prostitución» dependientes de la Municipalidad de Refresco, deberían quedar bajo el control de Carabineros - para hacer cumplir la ley de alcoholes y reprimir la delincuencia - y la Municipalidad anexarla a Taltal ${ }^{62}$.

Hacia fines del año 1925 se verificó una modificación de los límites de las comunas del departamento de Tocopilla, por medio del D.L. 803, de 22 de diciembre.

La señalada norma indicaba, en su artículo 1, que cada territorio comunal le correspondería una subdelegación completa, y la división administrativa comuna equivaldría a la división política llamada subdelegación. Al tenor de esta reforma la provincia de Antofagasta se dividía en cuatro departamentos, siendo el de Tocopilla, la comuna de Tocopilla integrada por las subdelegaciones

59 Oficio del Gobernador de Tocopilla, 4 de septiembre de 1925, al Intendente de Antofagasta. A.N., A.I.A., vol. 35.

$60 \mathrm{Ibid}$. El gobernador adjuntó un informe, Gobierno y Administración Interior del Departamento de Tocopilla. División que propone el Gobernador en respuesta a una Circular del señor Ministro del Interior sobre aplicación del articulo 93 de la nueva Constitución y a virtud de las consideraciones formuladas en la nota que precede. El informe en cuestión detallaba la inviabilidad de crear comunas rurales, la difícil situación de la comuna de Cobija, que vivía exclusivamente de la mina «Toldo», y que para que no pereciera por falta de rentas, «fue preciso dejar ubicada dentro de su territorio la salitrera "Dones", considerablemente distante de Gatico, que no embarca por este puerto ni un solo saco de salitre». El plan del gobernador significaba ahorrar al fisco \$12.000 anuales, al suprimirse los subdelegados de Cobija y Gatico. Ibid.

61 Oficio del Gobernador de Taltal, 14 de agosto de 1925 al Intendente de la Provincia. A.N., A.I.A., vol. 35.

62 Oficio del Gobernador de Taltal, 18 de julio de 1925, al Intendente de la Provincia. Ibid. 
1. Tocopilla, 2. Cobija y 3. El Toco; el de Antofagasta, compuesto por la comuna de Antofagasta, estaría comprendiendo las subdelegaciones: 1. Bellavista, 2. Prat, 3. Coloso, 4. Aguas Blancas, 5. Baquedano, 6. Sierra Gorda y 7. Mejillones; el de El Loa, con la comuna de Calama y las subdelegaciones: 1. Calama, 2. Chuquicamata, 3. Ascotán y 4. San Pedro de Atacama. Estos tres departamentos mantenían los límites determinados por el decreto 1.529 de 18 de marzo de 1925: el departamento de Taltal, con la comuna de Taltal y las antiguas subdelegaciones de: 1. Taltal, 2. Taltal (sic), 3. Esmeralda, 4. Santa Luisa, 5. Paposo, 6. Refresco, 7. Cachinal, 8. Vaquillas y 9. El Guanaco.

\section{LA PROVINCIA DE ANTOFAGASTA Y SUS DEPARTAMENTOS (EL NUEVO} DE EL LOA) HACIA 1928, Y SU FORMA DEFINITIVA DESPUÉS DE LA PÉRDIDA

DE LA PUNA DE ATACAMA

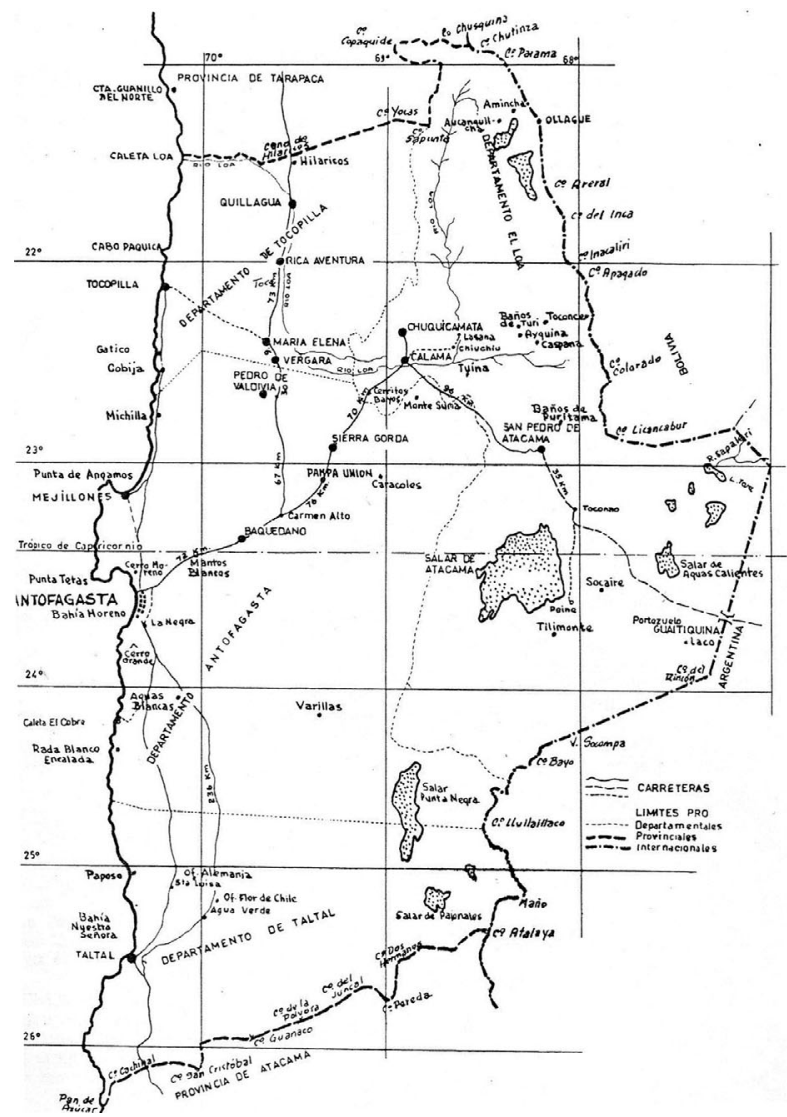

Fuente: Enrique Agullo, 1979: 7. 
La materia de la judicatura de la provincia de Antofagasta volvió a plantearse durante el año 1926, dirimiéndose, mediante la ley 4.079 de 23 de agosto, que el departamento de Taltal volviera a formar parte del distrito jurisdiccional de la Corte de Apelaciones de La Serena. Durante la dictadura del general Carlos Ibáñez del Campo (1927-1931) se impulsó una reforma político-administrativa que asumió determinados planteamientos que vimos en el seno de la Comisión que estudió la reforma constitucional que daría lugar a la Carta de 1925.

En efecto, mediante el DFL, 8582 de 28 de enero de 1928, fecha de su promulgación, se fijó una nueva división territorial de la república, teniendo presente:

1. ${ }^{\circ} \quad$ La conveniencia de dividir administrativamente al país, atendiendo a las necesidades efectivas y a las características propias de las diversas regiones y localidades, como ser, la situación geográfica, la población, los medios de comunicación, las facilidades que deben darse a la administración de justicia y las relaciones sociales y económicas de aquéllas, en forma que el núcleo administrativo corresponda a una zona unida por comunidad de intereses, constituyendo un centro natural de cultura y progreso.

2. ${ }^{\circ} \quad$ Que nuestra actual división administrativa obedece en muchos casos sólo a la tradición, a razones de política exclusivamente local o accidental o a otras circunstancias que no son permanentes ni pueden pesar frente a las necesidades generales del país o de las diversas regiones ${ }^{63}$.

La norma creaba dieciséis provincias y dos territorios el de Aysén y Magallanes y, en aquel marco, la provincia de Antofagasta se mantuvo con la capital en Antofagasta, integrada por los conocidos cuatro departamentos, Tocopilla, Loa, Antofagasta y Taltal. El nuevo ordenamiento político-administrativo comenzó a regir el 1 de febrero de 1928. A través del Decreto 8583, de 28 de enero de 1928, se estructuraron los departamentos de cada provincia. El departamento de Tocopilla quedaría integrado por las comunas de Tocopilla y Toco, correspondiéndole a Tocopilla las antiguas subdelegaciones: 1. Tocopilla y 2. Gatico, y a las del Toco, la antigua subdelegación: 3. Toco. Se disponía que las comunas de Tocopilla y Toco formaran una sola agrupación municipal, teniendo por cabecera la ciudad de Tocopilla. El departamento del Loa, con la comuna de Calama haciendo coincidir los límites del departamento con el de la comuna. El departamento de Antofagasta integrado por las comunas de Antofagasta, Mejillones, Sierra Gorda y Aguas Blancas. Las cuatro comunas formarían una sola agrupación municipal cuya cabecera era la ciudad de An-

63 DFL, 8582; fecha de publicación 28 de enero de 1928, fecha de promulgación 30 de diciembre de 1927, http://www.bcn.cl/lc/tinterna/index_html. 
tofagasta. El departamento de Taltal, con las comunas de Taltal y Catalina; éstas integrarían una sola agrupación municipal, cuya cabecera era la ciudad de Taltal ${ }^{64}$.

La persistencia de la denominación de «Antofagasta» para la provincia originó un cuestionamiento de una de las personalidades intelectuales más importantes de Antofagasta, monseñor Luis Silva Lezaeta. Según su parecer, este nuevo ordenamiento pudo subsanar el error de los legisladores que dieron el nombre de «Atacama» con capital Copiapó a la primera provincia que se creó al norte de Chile, pues «con buena lógica, la provincia donde ahora le escribo debe ser llamada Provincia de Atacama, conservando el nombre de Antofagasta para su capital». Atacama por el enorme desierto, Antofagasta por la designación del general boliviano Melgarejo, en recuerdo de la estancia que poseía en Antofagasta de la Sierra ${ }^{65}$. Tal juicio no fue acogido. A este cuadro general del mapa político-administrativo vino a sobreponerse determinadas modificaciones entre enero de 1930 y mayo de 1931, que afectaron los límites de los departamentos ${ }^{66}$.

El retorno a la institucionalidad democrática en 1932, llevó a Arturo Alessandri, en su segunda gestión política, a disponer por medio del decreto 4667 de 23 de noviembre de 1933, la necesidad de «refundir en un solo texto, las diversas disposiciones dictadas sobre división territorial en las provincias de Tarapacá y Antofagasta ${ }^{67}$. En consecuencia, la provincia de Antofagasta quedó integrada por cuatro departamentos Tocopilla (con dos comunas subdelegaciones Tocopilla y Toco), El Loa (con la comuna-subdelegación Calama), Antofagasta (con las comunas subdelegaciones 1. Antofagasta, 2. Mejillones, 3. Sierra y 4. Aguas Blancas) y Taltal (con las comunas-subdelegaciones de Taltal y Catalina $)^{68}$.

Mientras el país observó de nuevo reducirse el número de provincias; la de Antofagasta mostraba claramente una identidad poblacional, climática y de re-

64 Decreto 8583; DFL 8583, fecha de publicación 28 de enero de 1928, fecha de promulgación 30 de diciembre de 1927, http://www.bcn.cl/lc/tinterna/index_html.

65 Silva Lezaeta, LVII/61 (Santiago de Chile, 1928): 254.

66 V. gr. la ley 2335, de 22 de mayo de 1929, que determinó los departamentos del país; la ley 4798, de 24 de enero de 1930, que modificó el límite entre los departamentos de Tocopilla y Antofagasta; el decreto 128, de 16 de enero de 1931, que dividió el departamento de Tocopilla en comunas-subdelegaciones y distritos; el decreto 1619, de 8 de mayo de 1931, que dividió la comuna-subdelegación de Calama en distritos; el decreto 177, de 16 de enero de 1931, que dividió el departamento de Antofagasta en comunas-subdelegaciones y distritos y el decreto 1618 , de 8 de mayo de 1931, que dividió el departamento de Taltal en comunas-subdelegaciones y distritos.

67 Ministerio del Interior, 1933: 1.

68 Ministerio del Interior, 1933: 4. 
cursos mineros, sustancialmente distinta en el concierto del territorio nacional. Esta patente realidad quedó de manifiesto cuando la Corporación para el Fomento de la Producción, creada en 1939, examinó la eventual reestructuración de las regiones del país. Cabe acotar que los estudios llevados a cabo por un equipo multidisciplinario vieron luz con la publicación de la Geografía Económica de Chile, cuyos dos primeros volúmenes en 1950 plantearon la división del territorio nacional en seis regiones: Norte Grande, Norte Chico, Núcleo Central, Concepción y la Frontera, Región de los Lagos y Región de los Canales. Los otros dos volúmenes aparecieron en 1962. La idea de organizar el país en seis regiones obedecía a la asociación estrecha entre el paisaje, sus recursos naturales y sus gentes. Si bien fue un planteamiento académico-profesional en el seno de la CORFO, su concepción perduraba todavía a comienzos de la década de $1960^{69}$.

Los estudios que avalaban la asociación de las provincias de Tarapacá y Antofagasta, que daban forma y sentido al Norte Grande, bella expresión del poeta antofagastino Andrés Sabella, cuya novela homónima Norte Grande de 1944 dio nombre a la región, eran indiscutibles no sólo en el ámbito físico pues desde el límite con el Perú hasta el paralelo $27^{\circ} \mathrm{S}$, la orografía presentaba caracteres propios: Cordillera de los Andes, Depresión Intermedia y Cordillera de la $\operatorname{Costa}^{70}$, sino por el estrecho nexo entre el paisaje, las actividades mineras y la población ${ }^{71}$. Cabe acotar, empero, que uno de los aspectos más apremiantes para las regiones, como fue la institucionalidad de la Asamblea Provincial, recogida en la Constitución de 1925, nunca se dictó la ley respectiva para su funcionamiento. En los hechos, el Intendente, representante del Poder Ejecutivo central, asumió el gobierno de la provincia, acota Silva Cimma, subrogando las competencias de la Asamblea Provincial72. La disposición de Alessandri de 1933 fue, en definitiva, la que reguló a la provincia de Antofagasta hasta bien entrado el siglo XX.

\section{CONCLUSIONES}

La ley que estableció la provincia de Antofagasta encerró varios asuntos atingentes al territorio del desierto de Atacama. La ingente labor de los chile-

69 Corfo, 1965: XXIII-XXIV.

70 Corfo, 1965: 6.

71 Corfo, 1966: 6-8.

72 Citado por Juan Siglic Mazzalin, La provincia (Evolución de una idea), Editorial La Portada, Antofagasta, 1966, 29-35. 
nos y la violación formal por parte de Bolivia del Tratado de 1874, dio fundamentó a una de las nociones más arraigadas en la población chilena, la «reivindicación». En torno a este concepto, se cifró la proyección regional por un tratamiento igualitario en cuanto a la tributación salitrera con respecto a Tarapacá y su representación política. No obstante, el territorio significó - dado su confluencia como triple frontera en la franja oriental - negociaciones diplomáticas por parte de Chile, para su incorporación a su soberanía, con Bolivia y más tarde con Argentina. Fue la proyección internacional de la organización político administrativa. Igual relevancia tuvo los intereses económicos variados existentes en la zona con la estructuración interna de la provincia. Gravitó la importancia de las ciudades costeras por sobre las poblaciones del interior. La localización de los yacimientos de salitre, cobre y otros recursos mineros fueron cruciales para determinar los límites departamentales e incluso los comunales.

El territorio provincial debió sortear diversos ordenamientos que dieron cabida a las exigencias provenientes de la inflexión tanto minera como demográfica a principios del siglo XX. Así se pudo constatar la ampliación de departamentos y subdelegaciones, reordenándose las áreas que circunstancialmente — por los ciclos de bonanza y depresión salitrera - fueron desapareciendo como poblados y comunas.

Aun cuando en la discusión legislativa se barajaron las opciones de descentralización administrativa, en definitiva el territorio del desierto de Atacama se estructuró en el marco de un fuerte centralismo político-administrativo nacional que se replicó en el interior de la provincia.

Antofagasta no escapó en la implementación de los servicios públicos a las dificultades que afectaron a otros territorios. Las enormes distancias entre sus ciudades principales conspiraron en determinados asuntos, v.gr., los electorales, los judiciales. Sin embargo, logró forjar una identidad de paisaje, recursos y población, que fundamentó junto a Tarapacá — el territorio adverso a sus pretensiones en el siglo XIX - la noción clave del Norte Grande chileno. La historia se encargó de orientar a la legislación respecto a la coherencia íntima que existió desde los inicios entre el desierto, la minería y los rasgos de su población.

\section{BIBLIOGRAFÍA}

Agullo, Enrique, Antofagasta ciudad heroica, Antofagasta, Imprenta Agullo, 1979, Tomo I.

Anuario Hidrográfico de la Marina de Chile (Santiago de Chile, 1880, 1881), n.os 6-7. 
Andaluz, Horacio, Bases jurídicas para la reintegración marítima de Bolivia. La regla pacta sunt servanda como punto cero, Bolivia, Universidad Privada de Santa Cruz de la Sierra, 2002.

Anguita, Ricardo, Leyes promulgadas en Chile, 1811-1913, Santiago de Chile, Imprenta i Litografía i Encuadernación Barcelona, 1912, Tomos II-III.

Archivo del Arzobispado de Antofagasta, Libro V Copiador de Oficios, años 19121919.

Archivo Municipal de Antofagasta, Libro de Actas Municipales años 1885 a 1889.

Archivo de la Municipalidad de Calama, Volumen 8 de Actas Municipales año 1925.

Archivo Nacional, Archivo del Ministerio del Interior, volúmenes 1320, 869.

Archivo Nacional, Archivo de la Intendencia de Antofagasta, volúmenes 35, 46.

Arce, Isaac, Narraciones históricas de Antofagasta, Antofagasta, Corporación Pro Antofagasta, 2004.

Barros Van Buren, Mario, Historia Diplomática de Chile 1541-1938, Santiago de Chile, Editorial Andrés Bello, 1990.

Benedetti, Alejandro, «La Puna de Atacama como construcción geopolítica (18791900). La redefinición del mapa político argentino tras la guerra del Pacífico», $S i$ Somos Americanos. Revista de Estudios Tranfronterizos, VII/2 (Iquique, 2005): $155-183$.

Bertrand, Alejandro, Memoria sobre las cordilleras del desierto de Atacama y rejiones limitrofes, Santiago de Chile, Imprenta Nacional, 1885.

Cámara de Diputados, Legislatura Extraordinaria años 1879-1880, Santiago de Chile, Imprenta Nacional, 1880.

Cámara de Diputados, Legislatura Extraordinaria año 1881, Santiago de Chile, Imprenta Nacional, 1881.

Cámara de Diputados, Legislatura Ordinaria y Extraordinaria de 1881, Santiago de Chile, Imprenta Nacional, 1881.

Cámara de Diputados, Legislatura Ordinaria 1888. Santiago de Chile, Imprenta Nacional, 1888.

Cámara de Diputados, Legislatura Extraordinaria 1887-1888, Santiago de Chile, Imprenta Nacional, 1889.

Cámara de Diputados, Legislatura Ordinaria 1909, Santiago de Chile, Imprenta Nacional, 1909.

Cámara de Diputados, Legislatura Extraordinaria 1909-1910, Santiago de Chile, Imprenta Nacional, 1910.

Casassas, José M., Noticias sobre la Iglesia católica en la provincia de Antofagasta, Santiago, Editorial Orbe, 1967. 
Cobos Noriega, María Teresa, La división político-administrativa de Chile, 1541-1811, Valparaíso, Instituto de Historia, Universidad Católica de Valparaíso, 1989.

Corfo, Geografía Económica de Chile. Texto refundido, Santiago de Chile, Fundación Pedro Aguirre Cerda, 1965.

Corfo, Geografía Económica de Chile. Primer Apéndice, Santiago de Chile, Talleres Editorial Universitaria, 1966.

Espinosa Moraga, Óscar, La postguerra del Pacífico y la Puna de Atacama (18841899), Santiago de Chile, Editorial Andrés Bello, 1958.

Espinoza, Enrique, Geografía descriptiva de la República de Chile, Santiago de Chile, Imprenta, Litografía i Encuadernación Barcelona, 1903.

Gajardo Cruzat, Enrique, Album de Tarapacá y Antofagasta, Antofagasta, 1924.

González Errázuriz, Juan Ignacio, El Vicariato Castrense de Chile. Génesis histórica y canónica de su establecimiento. De la Independencia al conflicto eclesiástico de Tacna. 1810-1915. Estudio documental, Santiago de Chile, Universidad de los Andes, Colección Jurídica, 1996.

González Leiva, José Ignacio y Sagredo Baeza, Rafael, «Geografía y República. El ordenamiento político-administrativo del territorio chileno», Actas XXVI Congreso Nacional y XI Internacional de Geografía (Santiago de Chile, 2005): 345-355.

González Pizarro, José A., El Catolicismo en el desierto de Atacama. Iglesia, Sociedad, Cultura, 1557-1987, Antofagasta, Ediciones Universitarias, Universidad Católica del Norte, 2002.

González Pizarro, José A., «Municipio v/s Estado, como ejes estructurantes de la constitución del tesario regionalista del norte de Chile», Anuario de la Facultad de Ciencias Jurídicas, Universidad de Antofagasta, 2005 (Antofagasta, 2007): 70-80.

González Pizarro, José A., «Chile y Bolivia, 1810-2000», Pablo Lacoste (Compilador), Argentina Chile y sus vecinos, Argentina, Editorial Caviar Bleu, Colección Cono Sur, 2005, vol. I: 335-392.

http://www.bcn.cl/lc/tinterna/index_html

Ministerio del Interior, Actas Oficiales de las Sesiones celebradas por la Comisión y Subcomisiones encargadas del estudio del Proyecto de Nueva Constitución Política de la República, Santiago de Chile, Imprenta Universitaria, 1925.

Ministerio del Interior, Decreto $n .^{\circ} 4667$ de 23 de noviembre de 1933, que fija los límites de las provincias de Tarapacá y Antofagasta de sus departamentos, comunas, subdelegaciones y distritos, Santiago de Chile, Talleres Gráficos de La Nación, 1933.

Ministro de Relaciones Exteriores de Chile, Cuestión Chileno-Boliviana. Exposición sobre los motivos que justifican la reivindicación del territorio comprendido entre los paralelos $23^{\circ}$ y $24^{\circ}$ latitud sur, Valparaíso, Imprenta de la Patria, 1879. 
Rojas Delgado, Matías, El Desierto de Atacama i el territorio reivindicado, Antofagasta, Imprenta El Industrial, 1883.

Sanhueza, María Carolina, «La primera división político-administrativa de Chile, 1811-1826», Historia, II /41 (Santiago de Chile): 447-493.

Sanhueza Tohá, María, «Las poblaciones de la Puna de Atacama y su relación con los Estados Nacionales. Una lectura desde el Archivo», Revista de Historia Indígena, 5 (Santiago de Chile, 2001): 55-82.

Sanhueza Tohá, María y Gundermann K., Hans, «Estado, expansión capitalista y sujetos sociales en Atacama (1879-1928)», Estudios Atacameños, 34 (San Pedro de Atacama, 2007): 113-136.

Siglic Mazzalin, Juan, La provincia (Evolución de una idea), Antofagasta, Editorial La Portada, 1966.

Silva Lezaeta, Luis, «Atacama o Antofagasta», Revista Chilena de Historia y Geografía, LVII/ 61 (Santiago de Chile, 1928): 254-257.

Valencia Avaria, Luis, Anales de la República, Tomos I y II actualizados, Santiago de Chile, Editorial Andrés Bello, 1986.

\section{THE PROVINCE OF ANTOFAGASTA. CREATION AND CONSOLIDATION OF A NEW TERRITORY IN CHILE: 1888-1933}

The article examines diverse factors - geographic, economic, demographic, political and legal - which influenced the parliamentary debate and the subsequent creation of the province of Antofagasta under the government of Balmaceda. One of the most important differences of this province in comparison with other Chilean territories resulted from the municipal powers inherited from the Bolivian administration that contributed to the hardening of regionalist discourse in the face of the Chilean government's aim of juridical uniformity. The article reviews the different proposals for a political-administrative structure for the Antofagasta territory and the different modifications affecting it from 1888 until 1933. Emphasis is placed on the complexity of the territory at the local, national and international levels.

Key words: Chile, province, Atacama Desert, Antofagasta, Chilean laws. 